\title{
How often is genital yeast infection sexually transmitted?
}

\section{$+$}

R N THIN, MONICA LEIGHTON, M J DIXON

British Medical fournal, 1977, 2, 93-94

\section{Summary}

We analysed data from a computer-based bank of clinical records of patients seen in a clinic for sexually transmitted diseases over a three-year period to investigate the association between genital yeast infections and sexually transmitted diseases (STDs). We classified STDs as primary and secondary syphilis; gonorrhoea; lymphogranuloma venereum; trichomoniasis; scabies; pediculosis; genital herpes; warts; and molluscum contagiosum. Of a total of 2984 disease episodes among women, $1054(35.3 \%)$ included yeast infections, whereas only $382(6.9 \%)$ of 5501 episodes in heterosexual men were associated with yeast infections. We found a significant association between yeast infection and STD and non-specific genital infection (non-specific urethritis (NSU) and proctitis in men, and female contacts of men with NSU), which suggested that yeast infection was sexually acquired in 414 out of 1054 disease episodes in women $(39 \%)$ and 110 out of 382 episodes in heterosexual men $(29 \%)$. We conclude that sexually active patients with genital yeast infections should be screened for other STDs, particularly non-specific genital infection.

\section{Introduction}

Vaginal yeast infections are an increasing problem among patients attending general practitioners, gynaecologists, and venereologists, ${ }^{1}$ and vaginal yeasts are the most common infectious agents found in women attending clinics for sexually transmitted disease (STD) in England. ${ }^{2}$ According to Harris, ${ }^{3}$ it has been known for over 50 years that these organisms can be sexually transmitted, but they are less common in men than in women ${ }^{2}$ in contrast to other STDs such as syphilis and gonorrhoea. Nevertheless, yeasts are found in women with known STDs such as gonorrhoea. ${ }^{1}$ Yeasts may be readily identified in genital tract secretions in Gram-stained smears and on cultures using Sabouraud's medium, but the meaning of the yeasts common in symptom- and sign-free women is not clear. ${ }^{1}$

We used a computer-based data bank of clinical records ${ }^{4}$ to examine the association of genital yeast infections with sexually transmitted and other diseases in patients attending an STD clinic.

\section{Methods}

The data system we used recorded all the diagnoses made for each patient in each quarter of the year as single disease episodes. Diagnoses made on the same patient in different quarters were recorded as separate disease episodes. We studied the details of disease episodes recorded between 1 January 1972 and 31 December 1975. Patients

\section{St Bartholomew's Hospital, London EC1A 7BE}

R N THIN, MD, FRCPED, physician in charge, department of genital medicine

MONICA LEIGHTON, BA, MSC, statistician, computing unit for medical sciences

M J DIXON, computer programmer computing unit for medical sciences were divided into three groups: homosexual and heterosexual men, and women.

Classification-Diseases were classified as genital yeast infection; non-specific genital infection (NSGI), which included non-specific urethritis (NSU) and non-specific proctitis in men; female contacts of men with NSU were also regarded as having NSGI. ${ }^{5}$ We classified sexually transmitted disease (STD), non-sexually transmitted disease (NSTD), and other conditions in the following way: NSTD, which included chancroid, donovanosis, NSGI and arthritis, balanitis and vulvitis of unknown cause; STD, which included primary and secondary syphilis, gonorrhoea, lymphogranuloma venereum, trichomoniasis, scabies, pediculosis, genital herpes, warts, and molluscum contagiosum; and other conditions, meaning latent syphilis and anything not included in the other classifications. We treated NSGI as a separate STD as so many episodes were diagnosed. Patients in whom no disease was found were excluded.

Yeasts were identified by typical appearance on Gram-staining and by colonial morphology of cultures on Sabouraud's medium. The diagnosis of yeast infection was based on results of Gram-staining and culturing, or both, regardless of whether clinical features were present. We did not try to differentiate the species. The methods used for diagnosing gonorrhoea, non-specific genital infection, trichomoniasis, and genital herpes nifection have been recorded elsewhere. ${ }^{5-\text { - }}$

Suspected syphilis was confirmed by dark-ground examination and serological testing; tests used were Venereal Disease Reference Laboratory test, treponemal haemagglutination test, and fluorescent treponemal antibody absorption test. Genital warts, scabies, pediculosis, and molluscum contagiosum were diagnosed from the clinical appearance. Chancroid was diagnosed from clinical appearance supported by results of culturing, and lymphogranuloma venereum from clinical appearance and serological tests. Balanitis and vulvovaginitis of undetermined origin were diagnosed from clinical signs and exclusion of trichomonads and yeasts. There was no case of donovanosis.

\section{Results}

The total number of disease episodes was 9094 (table I), including 1462 yeast infections. There were 2984 episodes among women, 1054 $(35.3 \%)$ of which included yeast infections, while only $382(6.9 \%)$ of 5501 episodes in heterosexual men included yeast infections (table II). Yeast infections alone occurred in 617 women's episodes $(58.5 \%$ of all women's episodes with yeast infections) and in 263 heterosexual men's episodes $(68.8 \%$ of all heterosexual men's episodes with yeast infections). Although there were 338 episodes of NSTD, yeast infections occurred with only three of them (table II). There was also little association between yeast infections and other conditions, though there were about twice as many cases of other conditions as of NSTD.

The data in table II suggest an association between yeast infections and STD and NSGI, particularly among women and heterosexual men, as 414 out of 1054 women $(39 \%)$ and 110 out of 382 heterosexual men $(29 \%)$ had these two diseases in association with yeast infections. Yeast infections seemed not to be associated with NSTD and other conditions. Table III shows the number of disease episodes

TABLE I-Details of total number of disease episodes recorded

\begin{tabular}{|c|c|c|c|}
\hline Episodes & & No & $\%$ \\
\hline $\begin{array}{l}\text { Total } \\
\text { Genital yeast infection } \\
\text { STD } \\
\text { NSTD } \\
\text { NSGI }\end{array}$ & \begin{tabular}{ll|}
$\cdots$ & $\cdots$ \\
$\therefore$ & $\cdots$ \\
$\cdots$ & $\cdots$ \\
$\cdots$ & $\cdots$ \\
$\cdots$ & $\cdots$ \\
$\cdots$ & $\cdots$ \\
$\cdots$ & $\cdots$
\end{tabular} & 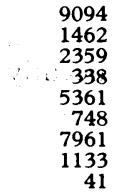 & $\begin{aligned} 100 \\
16 \cdot 1 \\
25 \cdot 9 \\
3 \cdot 7 \\
58 \cdot 9 \\
8 \cdot 2 \\
87 \cdot 5 \\
12 \cdot 5 \\
0.5\end{aligned}$ \\
\hline
\end{tabular}

STD $=$ sexually transmitted disease $; \mathrm{NSTD}=$ non-sexually transmitted disease NSGI = non-specific genital infection; other = latent syphilis and other infections not included in above categories. 
TABLE II-Distribution among different groups of patients of total episodes of disease and of yeast infections alone or in combination with other diseases

\begin{tabular}{|c|c|c|c|c|c|c|c|c|}
\hline \multirow[t]{2}{*}{ Infections* } & \multicolumn{2}{|c|}{$\begin{array}{l}\text { Homosexual } \\
\text { men }\end{array}$} & \multicolumn{2}{|c|}{$\begin{array}{l}\text { Heterosexual } \\
\text { men }\end{array}$} & \multicolumn{2}{|c|}{ Women } & \multicolumn{2}{|c|}{ Total } \\
\hline & No & "., & No & 0 & No & $\because "$ & No & " \\
\hline $\begin{array}{l}\text { Total episodes } \\
\text { Episodes with yeast }\end{array}$ & 609 & $6 \cdot 7$ & 5501 & $60 \cdot 5$ & 2984 & $32 \cdot 8$ & 9094 & 100 \\
\hline infectiont & 26 & $4 \cdot 3$ & 382 & 6.9 & 1054 & $35 \cdot 3$ & 1462 & $16 \cdot 1$ \\
\hline $\begin{array}{l}\text { Episodes with yeast } \\
\text { infection alone }++ \\
\text { Yeast infection and }\end{array}$ & 15 & $57 \cdot 7$ & 263 & $68 \cdot 8$ & 617 & 58.5 & 895 & $61 \cdot 2$ \\
\hline $\begin{array}{l}\text { Yeast infection and } \\
\text { one other disease }{ }_{+}^{+} \text {: } \\
\text { STD }\end{array}$ & & & & & & & & \\
\hline $\begin{array}{lll}\text { STD } & \cdots & \\
\text { NSTD } & \cdots & \end{array}$ & 8 & $30 \cdot 8$ & 17 & $\begin{array}{l}4 \cdot 4 \\
0 \cdot 3\end{array}$ & 123 & $\begin{array}{r}11 \cdot 7 \\
0.2\end{array}$ & $\begin{array}{r}148 \\
3\end{array}$ & $\begin{array}{r}10 \cdot 1 \\
0.2\end{array}$ \\
\hline $\begin{array}{lll}\text { NSGI } & \ldots & \ldots\end{array}$ & 2 & $7 \cdot 7$ & 86 & 22.5 & 268 & $25 \cdot 4$ & 356 & $24 \cdot 4$ \\
\hline $\begin{array}{l}\text { Other } \\
\text { Yeast infection and }\end{array}$ & & & 8 & $2 \cdot 1$ & 21 & $2 \cdot 0$ & 29 & $2 \cdot 0$ \\
\hline $\begin{array}{l}\text { two of above } \\
\text { diseases }+\end{array}$ & 1 & $3 \cdot 8$ & 7 & 1.9 & 23 & $2 \cdot 2$ & 31 & $2 \cdot 1$ \\
\hline $\begin{array}{l}\text { and any other } \\
\text { disease }+. .\end{array}$ & 11 & $42 \cdot 3$ & 119 & $31 \cdot 2$ & 437 & 41.5 & 567 & $38 \cdot 8$ \\
\hline
\end{tabular}

* See footnote to table I for explanation of disease classification.

+Percentage of episodes of yeast infection.

TABLE III-Numbers of disease episodes occurring in one category only with and without yeast infections

\begin{tabular}{|c|c|c|c|c|c|c|c|}
\hline \multirow[b]{2}{*}{$\begin{array}{l}\text { With yeast } \\
\text { infection } \\
\text { Alone... }\end{array}$} & \multirow[b]{2}{*}{ 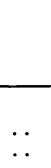 } & \multicolumn{2}{|c|}{$\begin{array}{l}\text { Sexually } \\
\text { transmitted } \\
\text { disease }\left({ }^{\circ}{ }_{0}\right)\end{array}$} & \multirow{2}{*}{$\begin{array}{c}\begin{array}{c}\text { Non-sexually } \\
\text { transmitted } \\
\text { disease }\left({ }_{0}^{\circ}\right)\end{array} \\
\begin{array}{c}3(1 \cdot 1) \\
270(98 \cdot 9)\end{array}\end{array}$} & \multicolumn{2}{|c|}{$\begin{array}{c}\text { Non-specific } \\
\text { genital } \\
\text { infection ("0) }\end{array}$} & \multirow{2}{*}{$\begin{array}{l}\text { Other }\left(\begin{array}{l}0 \\
.0\end{array}\right) \\
29(4.5) \\
622(95.5)\end{array}$} \\
\hline & & $\begin{array}{r}148 \\
1712\end{array}$ & $\begin{array}{r}(8 \cdot 0) \\
(92 \cdot 0)\end{array}$ & & $\begin{array}{r}356 \\
4462\end{array}$ & $\begin{array}{r}(7.4) \\
(92.6)\end{array}$ & \\
\hline Total & & 1860 & $(100)$ & $273(100)$ & 4818 & $(100)$ & $651(100)$ \\
\hline
\end{tabular}

$\chi \cdot 3=24 \cdot 6 . \quad P<0.001$.

that occurred in one category only, and those that occurred with only yeast infections in addition. We excluded disease episodes with diagnoses in several categories so that the columns of figures would be independent and could be compared by $\chi^{2}$ tests. The figures show a significant association between yeast infections and STD and NSGI.

\section{Discussion}

We found a more significant association between yeast infections and STD and NSGI than between yeast infections and NSTD or other conditions (table III). Our findings also reflect the figures reported by the Department of Health and Social Security² with more genital yeast infections occurring among women than among men. A patient may have more than one STD at a time. For example, Barlow et al, ${ }^{8}$ reported trichomoniasis in $33^{\circ}$ of 165 women patients with gonorrhoea, while $41^{\circ}{ }_{0}$ of them had yeast infections. Willmott ${ }^{\circ}$ found other infections in $33.8^{\circ}$, of 207 women with genital yeast infection.

We believe that the significant association of yeast infections with STDs and NSGI compared with NSTDs or other conditions supports the idea that genital yeast infection is sexually transmitted, despite the presence of many more diagnoses of STD and NSGI than of NSTD and other conditions. Our figures suggest that yeast infection was sexually acquired in approximately $39^{\circ}{ }_{0}$ of women's episodes and $29^{\circ}{ }_{0}$ of heterosexual men's episodes. Furthermore, they show that any sexually active patient with genital yeast infection whether symptomatic or not should be screened for other STDs, especially for NSGI. Others might adopt a slightly different classification of conditions into STD, NSTD, and others but we believe the conclusions would be the same.

\section{References}

${ }^{1}$ British Medical fournal, 1976, 1, 357.

${ }^{2}$ Department of Health and Social Security, Report of the State of the Public Health for the Year 1975. London, HMSO, 1976.

${ }^{3}$ Harris, J R W, in Recent Advances in Sexually Transmitted Diseases, ed R S Morton and J R W Harris, p 231. Edinburgh, Churchill Livingstone, 1975.

4 Thin, R N, and Smith, D M, British fournal of Venereal Diseases, 1976, 52, 161.

${ }^{5}$ Burns, D C M, et al, British fournal of Venereal Diseases, 1975, 51, 314

- Alani, M D, et al, British fournal of Venereal Diseases, 1977, 53, 88 .

7 Atia, W A, and Thin, R N, British fournal of Venereal Diseases, 1975, 51, 331.

${ }^{8}$ Barlow, D, et al, British fournal of Venereal Diseases, 1976, 52, 326.

- Willmott, F E, British fournal of Venereal Diseases, 1975, 51, 119.

(Accepted 3 May 1977)

\section{SIDE EFFECTS OF DRUGS}

\section{Disulfiram hepatotoxicity}

Disulfiram is extensively used as supportive treatment in chronic alcoholism. Its side effects are mainly neuropsychiatric and gastrointestinal, ${ }^{1}$ though two cases $^{23}$ of hepatotoxicity due to disulfiram have been reported in the United States and one in Norway. ${ }^{4}$

Alcoholism and liver disease are closely connected, and liver impairment due to disulfiram may therefore be easily overlooked. We describe here six patients whose liver impairment may have been due to disulfiram treatment.

\section{Case 1}

A 38-year-old woman who had abused alcohol for 10 years was started on disulfiram treatment (dose unknown). After three weeks she developed anorexia and vomiting and then jaundice. On admission she was comatose. She received standard treatment for coma plus corticosteroids and recovered consciousness after two days. No liver biospy was performed. Disulfiram hepatotoxicity was not suspected and treatment was restarted two years later. After about two weeks she developed fever, anorexia, and vomiting. Her general condition was good. On admission bilirubin was $291 \mu \mathrm{mol} / 1(17.0 \mathrm{mg}$ $100 \mathrm{ml}$ ), prothrombin $32 \%$ of normal, alanine aminotransferase (SGPT) $372 \mathrm{U} / 1$, alkaline phosphatase $114 \mathrm{U} / 1$. Her liver function was only moderately impaired and returned to normal when disulfiram treatment was stopped. A liver biopsy two weeks later was normal. Three weeks after admission she was challenged with disulfiram. She developed anorexia, vomiting, abdominal pain, and fever. The results of the liver tests are shown in fig 1 . A liver biopsy five days later showed portal enlargement with infiltration of inflammatory cells and eosinophil leucocytes and focal necrosis in the parenchyma. The symptoms lasted for six days. Liver biopsies five and 11 years later were completely normal.

\section{Case 2}

A 69-year-old woman was started on disulfiram (200 $\mathrm{mg}$ three times a week) because she felt "queer" when drinking alcohol. A month earlier a liver biopsy had shown normal liver histology. After six months' treatmen she complained of fatique and abdominal distension. Jaundice was observed three weeks later and after a further three weeks she lapsed into hepatic coma. On admission to this department she was comatose. Bilirubin was $451 \mu \mathrm{mol} / 1(26.4 \mathrm{mg} / 100 \mathrm{ml})$, prothrombin $19 \%$, SGPT $97 \mathrm{U} / 1$, and alkaline phosphatase $79 \mathrm{U} / 1$. Five exchange transfusions were performed but she died of liver failure.

At necropsy the liver was small, weighing $550 \mathrm{~g}$, with a nodular surface. Microscopy showed preserved lobular architecture with liver cell necrosis and marked fibrosis in the portal tracts.

\section{Case 3}

Disulfiram treatment $(200 \mathrm{mg} /$ day $)$ was started six months after this 41-year-old man began to abuse alcohol. His liver had been macroscopically normal 10 years earlier when he underwent operation for duodenal ulcer.

After three to four weeks' treatment he complained of abdominal cramps 